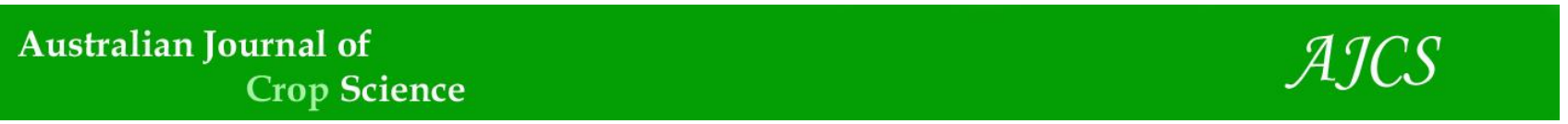

AJCS 14(09):1433-1442 (2020)

ISSN:1835-2707

doi: 10.21475/ajcs.20.14.09.p2464

\title{
Grain yield, stability and bacterial brown spot disease of dark red kidney dry bean (Phaseolus vulgaris L.) genotypes across six environments in South Africa
}

\author{
Venâncio Salegua ${ }^{182^{*}}$, Rob Melis ${ }^{1}$, Deidré Fourie ${ }^{2}$, Julia Sibiya ${ }^{1}$, Cousin Musvosvi ${ }^{1}$ \\ ${ }^{1}$ University of KwaZulu-Natal, School of Agricultural, Earth and Environmental Sciences, Private Bag X01, Scottsville \\ 3209, Pietermaritzburg, South Africa \\ ${ }^{2}$ Agricultural Research Council - Grain Crops Institute, Private Bag X1251, Potchefstroom 2520, South Africa
}

*Corresponding author: salegua@gmail.com

\begin{abstract}
Dry bean (Phaseolus vulgaris L.) is grown under an extensive range of agro-climatic conditions and is an essential source of protein and income globally. This study aimed to evaluate yield performance, stability, and bacterial brown spot (BBS) disease resistance of fourteen dark red kidney genotypes across environments in South Africa namely Carolina, Clarens, Cedara, Middelburg, Potchefstroom, and Warden. Analysis of variance (ANOVA), additive main effects and multiplicative interaction (AMMI) and the genotype plus genotype by environment interaction (GGE-biplot) analysis were used to evaluate grain yield performance, stability, and BBS disease resistance. The AMMI ANOVA revealed that mean squares for grain yield and BBS severity for the environment, genotype, and genotype by environment interaction were highly significant $(P<0.001)$. Four interaction principal components (IPCA1 - 4) for grain yield and IPCA1 for BBS severity were highly significant $(P<0.001, P<0.01)$. Genotype G12 showed broad adaptation for both high grain yield and low BBS severity across the six environments, while genotypes G08, G06, G03, G02, G05, and G04 had specific adaption for high grain yield and low BBS severity. These genotypes recorded grain yield above the grand mean and the best check cultivar, both with $1.43 \mathrm{t}$ ha-1, and BBS severity below the grand mean (31.90\%) and the best check (48.89\%). The genotypes identified with either broad or specific adaptation can be released in the environments they are adapted to, or used as parents in breeding programmes aiming to improve grain yield and BBS disease resistance of dry bean for farmers in South Africa.
\end{abstract}

Keywords: ASV, grain yield, bacterial brown spot, broad and specific adaption.

Abbreviations: AEC_Environment Coordinate; AMMI_Additive Main Effect and Multiplicative Interaction; ARC-GCIGC Agricultural Research Council-Grain Crops Institute; Germplasm Collection; ARC-GCIBP_Agricultural Research Council-Grain Crops Institute Breeding Program; BBS_Bacterial Brown Spot; CIAT_Centre for International Tropical Agriculture; DF_Days to flowering; DRK_Dark Red Kidney; GEI_Genotype by Environment Interaction; GGE_ Genotype Main Effects and Genotype by Environment Interaction; IPCA_Interaction Principal Components Axis; Pss_Pseudomonas syringae vs syringae; RIL_Recombinant Inbreed Lines

\section{Introduction}

Dry bean (Phaseolus vulgaris L.) $(2 \mathrm{n}=2 \mathrm{x}=22)$, is the third most important source of protein and income crop worldwide and is produced under an extensive series of agro-climatic conditions, surpassed only by soybean (Glycine max (L.) Merr.) and peanut (Arachis hypogea L.) (González et al., 2006; Dia et al., 2016). The crop is grown between $52^{\circ} \mathrm{N}$ and $32{ }^{\circ} \mathrm{S}$ up to an altitude of $3000 \mathrm{~m}$ (Kimani et al., 2005). Southern and Eastern Africa are main production regions with approximately 3.7 million ha of arable land per year under dry beans (Kimani et al., 2005). In South Africa this crop is largely grown in the Free State $(43 \%)$, Mpumalanga (23\%), Limpopo (10\%) provinces with the remaining produced in the KwaZulu-Natal, Gauteng, North West and Eastern Cape provinces (Muedi et al., 2015). These agroecological regions are different in terms of temperature, rainfall and soil fertility (Muedi et al., 2015). The mean grain yield in South Africa is $1.40 \mathrm{t} \mathrm{ha}^{-1}$ (Dlamini et al., 2017) and is relatively low compared with North America $\left(\sim 3.00 \mathrm{t} \mathrm{ha}^{-1}\right)$ (Kimani et al., 2005; FAO, 2014). The grain yield losses caused by Pseudomonas syringae pv.syringae (Pss) can be up to 55\% (Serfontein, 1994; Muedi et al., 2015). The most popular grain types grown in South Africa are red speckled sugar ( $75 \%$ of the local market share) and small white canning beans (20\% of the local market share (Muedi, 2015). Dark Red Kidney beans (DRK) are mainly imported for canning purposes. There is, however, a growing market for these beans as consumer demand for convenience foods is increasing. Foreign cultivars are poorly adapted and highly susceptible to diseases in South Africa and a breeding programme was, therefore, initiated at ARC-GC to develop well-adapted, disease resistant DRK beans for local production. The genotype by environment interaction (GEI) reveals the changes of comparative performance of genotypes over sites because of genotype, the environment, 
or both (Mortazavian et al., 2014). The GEI complicates the identification and selection of suitable genotypes for a specific environment or across environments. The GEI analysis is used to identify lines that perform consistently well over a range of sites for broad and specific adaption (Dia et al., 2016). The statistical methods for stability evaluation include univariate and multivariate analysis (Chipeta et al., 2017). The AMMI analysis is used for quantifying GEI and can extract genotype and environment main effects from the total variation, and uses the remaining interaction component (GEI) for principal component analysis (Abuali et al., 2014; Oladosu et al., 2017). The failure of the AMMI analysis to generate expectation for stability measure (ranking genotypes) motivated the computation of the AMMI stability value (ASV) (Purchase et al., 2000). A lower ASV reveals that a genotype has a wide adaptation and higher ASV reveals that a genotype has specific adaptation (Agyeman et al., 2015). The genotype main effect plus genotype by environment interaction biplot (GGEBiplot) is a multivariate analysis tool, which is based on the genotype mean performance and stability over a range of sites (Dia et al., 2016; Oladosu et al., 2017). Broad and specific adapted dry bean cultivars with bacterial brown spot (BBS) disease resistance would offer South African farmers a sustainable way of improving yields. This study aimed to evaluate the grain yield performance, stability parameters and resistance to BBS disease of advanced breeding lines across six environments in South Africa.

\section{Results}

Analysis of variance of grain yield and BBS severity across six environments

The ANOVA across sites indicated that the mean squares for genotypes, environments, and GEI were significant $(P<0.001)$ for grain yield and BBS severity (Table S3). The environments (Fig 1) had the highest contribution to the grain yield total sum of squares (68.29\%) followed by GEI (15.81\%) and lastly genotype $(5.62 \%)$, while the BBS severity total sum of squares were partitioned as $4.26 \%, 65.84 \%$ and $9.13 \%$ for environment, genotype, and GEI, respectively (Table S3).

\section{Mean grain yield and BBS severity across six environments}

The grain yield mean and BBS severity across six environments are presented in Table S4. The mean grain yield of genotypes and BBS severity were $1.43 \mathrm{t} \mathrm{ha}^{-1}$ and $33.53 \%$, respectively. The dry bean genotypes performed differently across the locations. Potchefstroom had the highest mean yield, and the lowest BBS severity, and Middelburg had the lowest mean yield and the highest BBS severity. Genotypes G08 $\left(1.77 \mathrm{t} \mathrm{ha}^{-1}\right)$, G06 (1.70 $\left.\mathrm{t} \mathrm{ha}^{-1}\right), \mathrm{G03}$ $\left(1.62 \mathrm{t} \mathrm{ha}^{-1}\right), \mathrm{G02}\left(1.56 \mathrm{t} \mathrm{ha}^{-1}\right), \mathrm{G} 05\left(1.48 \mathrm{t} \mathrm{ha}^{-1}\right), \mathrm{G} 12(1.46 \mathrm{t}$ $\left.\mathrm{ha}^{-1}\right)$, and G04 (1.45 tha $\left.{ }^{-1}\right)$ had grain yield mean above the grand mean and the best performing cultivar (both $1.43 \mathrm{t}$ ha $\left.{ }^{1}\right)$ and a BBS severity less than the grand mean (31.90\%) and the best performing cultivar (48.89\%) across six environments.

\section{AMMI analysis for grain yield and bacterial brown spot severity}

The AMMI analysis of variance with four IPCAs for grain yield and one for BBS severity are shown in Table 1 . The IPCA 1-4 axes for grain yield were significant $(\mathrm{P}<0.001, \mathrm{P}<0.01)$ and explained $43.56 \%, 23.47 \%, 21.72 \%$ and $8.19 \%$ of the total GEI sum of squares, respectively, and cumulatively accounted for $96.94 \%$ of GEI variation. The residual $3.06 \%$ of the GEI sum of squares was not significant. The grain yield IPCA1 and IPCA2 sum of squares cumulatively contributed $67.03 \%$ of the total GEI. The IPCA1 explained $61.13 \%$ for BBS severity of the total GEI sum of squares, and the residual $38.38 \%$ was not significant.

\section{Mean yield, BBS severity and AMMI stability value}

The mean, IPCAs scores and AMMI stability value (ASV) of grain yield and BBS severity are presented in Table 2 .

The grain yield ranged from $1.08 \mathrm{t} \mathrm{ha}^{-1}$ (G10) to $1.77 \mathrm{t} \mathrm{ha}^{-1}$ (G08), while the BBS severity ranged from G08 $(21.67 \%$ to G14 (53.06\%). The ASV for grain yield ranged between 0.14 (G09) and 1.19 (G14). Genotypes G09 (0.14), G13 (0.23), G04 (0.44), G12 0.46), G05 (0.54), G11 (0.55) and G01 (0.57) revealed broad adaptation, while genotypes G10 (1.09), G07 (1.05), G02 (0.91), G06 (0.88), G03 (0.86) and G08 (0.74) revealed specific adaptation. Furthermore, the genotype G12 $\left(1.46 \mathrm{t} \mathrm{ha}^{-1}\right)$ had low ASV for grain yield and low BBS severity, while genotype G08 (1.77\%), G06 (1.70\%), G03 (1.62\%), G02 (1.56\%), G05 (1.48\%) and G04 (1.45 $\left.\mathrm{t} \mathrm{ha}^{-1}\right)$ had high ASV and high grain yield, and revealed specific adaptation.

\section{Mean yield and AMMI stability value scores for environments}

The mean yield of genotypes over environments ranged from $1.04 \mathrm{t} \mathrm{ha}^{-1}$ at Carolina to $2.84 \mathrm{t} \mathrm{ha}^{-1}$ at Potchefstroom (Table 3 ). The grain yield ranking of environments indicated that Potchefstroom had the highest yield (2.84\%), followed by Warden and Clarens, while Carolina $\left(1.04 \mathrm{t} \mathrm{ha}^{-1}\right)$ had the lowest grain yield. Potchefstroom had the lowest BBS severity (30.71\%), and Middelburg and Warden had the highest BBS severity (37.50\%). The ASV for grain yield ranged between 0.15 (Cedara) to 1.66 (Middelburg), while for BBS severity ranged between 0.64 (Cedara) to 3.17 (Warden) (Table 3). Cedara had the lowest ASV for grain yield and BBS severity and was the most stable environment, while Warden, Middelburg, and Carolina had the highest ASV and were the least stable environments.

\section{Rank of genotypes per environment}

The best four performing genotypes for grain yield and BBS severity for each environment are presented in Table 4. The rank of genotypes performance changed across the environments and indicated the crossover GEI for grain yield and BBS severity.

\section{Mean grain yield vs IPCA1}

Fig 2. is a graph of AMMI IPCA1 scores against grain yield mean over six environments. The genotypes with no or little interactions have low IPCA1 scores, while larger IPCA scores indicate that they were highly interactive. Environments with IPCA1 scores close to zero have less discriminating ability. The lower potential environments and the lower yielding genotypes were observed to the left of the vertical dotted line. In contrast, high yielding genotypes are to the right of the dotted vertical line. Genotypes with IPCA1 scores close to zero had low interaction over sites, whereas the 
genotypes with high magnitude IPCA1 scores, either positive or negative signal, were greatly interactive. Genotypes G04 and $\mathrm{G} 12$ were both high yielding and stable, while genotypes G08, G6, G02, G03, and G05 were high yielding and unstable. Potchefstroom, Middelburg, and Clarens were further away from the origin and were therefore unstable environments, though most discriminating.

\section{Mean bacterial brown spot severity vs IPCA1}

AMMI 1 with IPCA 1 and BBS severity across six environments are shown in Fig 3. The genotypes with no or little interactions have low IPCA 1 scores, while larger IPCA scores indicates that they were highly interactive. Environments close to zero have less discriminating ability. The lower potential environments and the genotypes with low BBS severity were observed to the left of the vertical line, and in contrast, genotypes with high BBS severity are to the right of the vertical lines. Genotypes with IPCA 1 scores nearby zero had low interaction over locations, whereas the genotypes with large IPCA 1 scores, either positive or negative signal were highly interactive. Several genotypes scattered on the left of the quadrant and were BBS disease resistant. Genotypes G13, G014, G11 and G10 had high BBS severity and were unstable, while G08, G06, G02, G5, G07 and G12 had low BBS severity and were stable. Warden, Middelburg and Carolina were further away from the origin and were therefore very unstable, though most discriminating.

\section{IPCA1 vs IPCA2 plot for grain yield}

The AMMI biplot analysis indicates that the initial two IPCAs axes explained $67.01 \%$ of the total variation (Fig 4). Potchefstroom and Clarens had long vectors in the biplot. Cedara had a short vector and was therefore the most stable environment. Genotype G4 had specific adaptation for Clarens. Genotypes $\mathrm{G} 10$ and G07 had specific adaptation for Potchefstroom. Genotypes G02, G03, G05 and G06 performed better at Middelburg. Genotypes G11 and G01 performed well at Warden. Genotypes G09, G12, G04 and G05 were close to centre of the biplot and showed broad adaptation (Fig 4).

\section{GGE biplot for grain yield and BBS severity}

\section{Mega-environments for grain yield}

The best performing genotypes and mega-environments for grain yield are shown in (Fig 5). The polygon view was constructed by genotypes G10, G14, G6 and G3, which were furthest from the centre. The IPCAs 1 and 2 cumulatively explained $67.13 \%$ of the total variation. The GGE biplot indicated the presence of three mega-environments. Potchefstroom formed its own mega-environment, while Middelburg, Carolina and Cedara formed another one. The last mega-environment comprised Warden and Clarens. The first mega-environment comprised environment Potchefstroom with genotypes G07, G10, G13, G11 and G09. The second mega-environment had environments Cedara, Carolina and Middelburg with genotypes such as G06, G08, G12, G02, G03 and G05 performing well, while G14, G04 and G01 were adapted to the third mega-environment. Genotypes G10 and G14 performed poorly across all environments.

\section{Mega-environments for BBS disease severity}

The best performing genotypes and mega-environments for BBS severity are presented in (Fig 6). The polygon view was constructed by genotypes $\mathrm{G} 10, \mathrm{G} 11, \mathrm{G} 01, \mathrm{G} 14, \mathrm{G} 13, \mathrm{G} 05$, $\mathrm{G02}, \mathrm{G} 06$ and $\mathrm{G03}$, which were furthest from the centre. The IPCA 1 and 2 explained $67.13 \%$ of the total variation. The GGE biplot indicated the presence of three megaenvironments for BBS severity. Warden formed its own mega-environment, while Carolina, Clarens and Potchefstroom formed another one. The last megaenvironment comprised Cedara and Middelburg. The first mega-environment combined environment Warden with genotype G10.

\section{Mean grain yield and stability across environments}

The GGE comparison biplot (Fig. 7) shows the average environment coordinate (AEC) abscissa for the genotypes and interaction with the six environments for grain yield. The further away the genotype is from the AEC abscissa, the more unstable and vice versa. The ideal genotype had higher mean yield performance and higher stability over environments. Genotypes were observed above and below the AEC ordinate line. Genotypes $\mathrm{GO} 4$ to $\mathrm{G08}$ were above AEC ordinate and had high mean performance, whereas G14 to G10 were below AEC ordinate had low mean performance, with the gap of $0.25 \mathrm{Kg} \mathrm{ha}^{-1}$ between high and low mean grain yield performance (Fig. 7). Genotypes G09, $\mathrm{G} 12, \mathrm{G} 07, \mathrm{G} 13$ and $\mathrm{G} 11$ had short vectors running from the $A E C$ indicating that they were relatively stable while genotypes G14, G06, G08, G03 and G02 had the longest vectors and highly interactive with the environment.

\section{Mean bacterial brown spot severity and stability across environments}

The GGE comparison biplot (Fig 8) shows the average environment coordinate ( $A E C$ ) abscissa for the genotypes and interaction with the six environments for BBS severity. The further away the genotype is from the AEC abscissa, the more unstable and vice versa. The ideal genotype had low mean BBS severity and high stability over environments. Genotypes were observed above and below the AEC ordinate line. Genotypes G07 to G08 were below AEC ordinate and had low mean BBS severity, while G10 to G14 were above $A E C$ ordinate and had high mean BBS severity (Fig 8). Genotypes such as G08, G03, G04, G09, G12, G07 and G13 had short perpendicular projections from the AEC abscissa indicating that they were relatively stable while genotypes G02, G05, G06, G10, G11, G01 and G14 had the longest perpendicular projections and were highly interactive with the environment.

\section{Stability coefficients}

The yield stability coefficients and ranking of genotypes over six locations are given in Table S5. A genotype was considered stable when the univariate stability coefficient of grain yield did not differ significantly from zero. Large stability coefficients indicated genotypes with specific adaptation to high yielding environments, while low stability coefficient indicated genotypes with broad adaptation over environments. 
Table 1. AMMI analysis of variance for grain yield and bacterial brown spot severity of DRK dry bean lines across six environments.

\begin{tabular}{|c|c|c|c|c|c|c|c|c|c|c|}
\hline \multirow[b]{2}{*}{ Source } & \multicolumn{5}{|c|}{ Grain yield } & \multicolumn{5}{|c|}{ BBS severity } \\
\hline & DF & SS & MS & $\begin{array}{l}\text { Treat } \\
\exp (\%)\end{array}$ & $\begin{array}{l}\text { GEI } \\
\text { explained } \\
\text { (\%) }\end{array}$ & DF & SS & MS & $\begin{array}{l}\text { Treat } \\
\text { exp } \\
(\%) \\
\end{array}$ & $\begin{array}{l}\text { GEI } \\
\text { exp } \\
(\%) \\
\end{array}$ \\
\hline Total & 251 & 149.93 & 0.60 & - & - & 251 & 48857.00 & 194.60 & - & - \\
\hline Treatment & 83 & 136.33 & $1.64^{* * *}$ & - & - & 83 & 41590.00 & $501.10 * * *$ & - & - \\
\hline Gen (G) & 13 & 8.81 & $0.68^{* * *}$ & 6.46 & - & 13 & 34565.00 & $2658.90^{* * *}$ & 83.11 & - \\
\hline $\operatorname{Env}(\mathrm{E})$ & 5 & 102.38 & $20.48^{* * *}$ & 75.10 & - & 5 & 2083.00 & $416.60^{* * *}$ & 5.01 & - \\
\hline $\operatorname{Rep}(\operatorname{Rep})$ & 12 & 2.20 & $0.18^{* *}$ & - & - & 12 & 692.00 & 57.60 & - & - \\
\hline GEI & 65 & 25.14 & $0.39 * * *$ & 18.44 & - & 65 & 4942.00 & $76.00^{* *}$ & 11.88 & - \\
\hline IPCA 1 & 17 & 10.95 & $0.64^{* * *}$ & - & 43.56 & 17 & 3021.00 & $177.70 * * *$ & - & 61.13 \\
\hline IPCA 2 & 15 & 5.90 & $0.39 * * *$ & - & 23.47 & - & - & - & - & - \\
\hline IPCA 3 & 13 & 5.46 & $0.42 * * *$ & - & 21.72 & - & - & - & - & - \\
\hline IPCA 4 & 11 & 2.06 & $0.19 * *$ & - & 8.19 & - & - & - & - & - \\
\hline Residual & 9 & 0.77 & 0.09 & - & 3.06 & 48 & 1921.00 & 40.00 & - & 38.88 \\
\hline Error & 156 & 11.41 & 0.07 & - & - & 156 & 6575.00 & 42.10 & - & - \\
\hline
\end{tabular}

$* \mathrm{P}<0.05,{ }^{* *} \mathrm{P}<0.01, * * * \mathrm{P}<0.001, \mathrm{DF}=$ Degrees of freedom, CV = Coefficient of variation, $\mathrm{SS}=$ Sum of squares, MS = Mean sum of squares, Treat exp (\%) $=$ Treatment explained in \%, GEI exp=GEI explained in \%, IPCA= Interaction principal component axis scores and BBS=Bacterial brown spot.

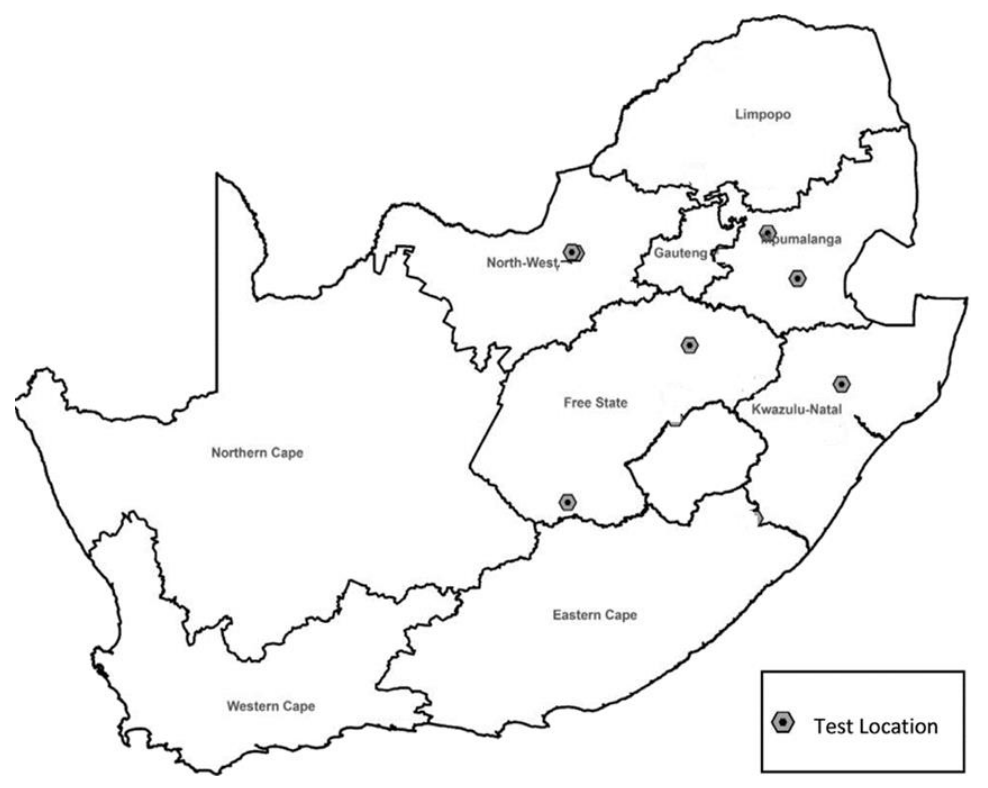

Fig 1. Agricultural Research Council DRK dry bean locations used for GEl evaluations.

Table 2. The mean, IPCA scores and ASV of grain yield and BBS severity of each DRK dry bean lines evaluated across six environments.

\begin{tabular}{lllllllll}
\hline Genotype & $\begin{array}{l}\text { Grain yield } \\
\text { Mean } \\
\mathrm{t} \mathrm{ha}^{-1}\end{array}$ & IPCAg[1] & IPCAg[2] & IPCAg[3] & IPCAg[4] & ASV & $\begin{array}{l}\text { BBS severity } \\
\text { Mean } \\
\text { (\%) }\end{array}$ & IPCAg[1] \\
\hline G01 & 1.37 & 0.30 & -0.09 & 0.18 & 0.07 & 0.57 & 50.28 & -1.92 \\
G02 & 1.56 & -0.49 & 0.11 & 0.16 & 0.18 & 0.91 & 22.22 & 1.96 \\
G03 & 1.62 & -0.45 & 0.22 & 0.37 & -0.18 & 0.86 & 24.72 & 0.10 \\
G04 & 1.45 & 0.12 & -0.37 & 0.16 & 0.06 & 0.44 & 24.72 & 0.81 \\
G05 & 1.48 & -0.29 & 0.11 & 0.15 & 0.07 & 0.55 & 23.89 & 2.18 \\
G06 & 1.70 & -0.47 & 0.03 & 0.33 & -0.07 & 0.88 & 23.33 & 1.50 \\
G07 & 1.35 & 0.52 & 0.42 & 0.05 & 0.05 & 1.05 & 30.00 & 0.51 \\
G08 & 1.77 & -0.39 & -0.13 & -0.80 & -0.39 & 0.74 & 21.67 & 0.80 \\
G09 & 1.13 & -0.03 & -0.13 & -0.39 & 0.03 & 0.14 & 27.50 & 0.35 \\
G10 & 1.08 & 0.47 & 0.64 & -0.01 & -0.42 & 1.09 & 40.28 & -2.94 \\
G11 & 1.28 & 0.30 & -0.02 & -0.19 & 0.36 & 0.55 & 46.67 & -2.43 \\
G12 & 1.46 & -0.22 & -0.23 & 0.07 & 0.09 & 0.46 & 28.89 & 0.07 \\
G13 & 1.35 & 0.10 & 0.14 & -0.32 & 0.45 & 0.23 & 52.22 & 0.16 \\
G14 & 1.43 & 0.52 & -0.7 & 0.24 & -0.29 & 1.19 & 53.06 & -0.94 \\
\hline
\end{tabular}




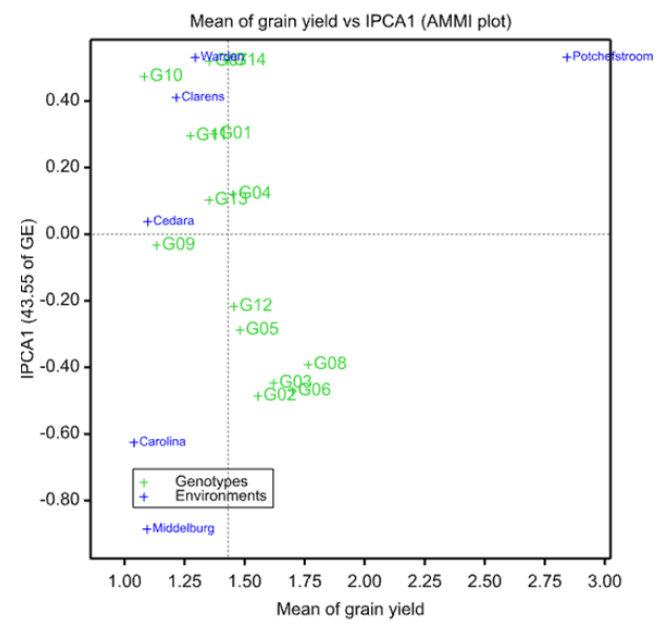

Fig 2. AMMI biplot showing the genotype adaptation based on grain yield and IPCAs scores across six environments.

Table 3. The mean, IPCAs scores and ASV for grain yield and BBS severity of DRK dry bean lines evaluated in each environment.

\begin{tabular}{|c|c|c|c|c|c|c|c|c|}
\hline \multirow[b]{2}{*}{ Environment } & \multicolumn{6}{|c|}{ Grain yield } & \multicolumn{2}{|c|}{ BBS severity } \\
\hline & $\begin{array}{l}\text { Mean } \\
\mathrm{t} \mathrm{ha}^{-1}\end{array}$ & IPCAe[1] & IPCAe[2] & IPCAe[3] & IPCAe[4] & ASV & Mean (\%) & IPCAe[1] \\
\hline Carolina & 1.04 & -0.63 & -0.12 & -0.85 & -0.27 & 1.17 & 31.67 & 2.91 \\
\hline Cedara & 1.10 & 0.04 & -0.13 & -0.13 & 0.79 & 0.15 & 32.74 & 0.64 \\
\hline Clarens & 1.22 & 0.41 & -0.81 & 0.20 & -0.11 & 1.11 & 31.07 & 1.41 \\
\hline Middelburg & 1.10 & -0.89 & 0.21 & 0.72 & -0.05 & 1.66 & 37.50 & -3.04 \\
\hline Potchefstroom & 2.84 & 0.53 & 0.82 & -0.14 & -0.01 & 1.28 & 30.71 & 1.24 \\
\hline Warden & 1.30 & 0.53 & 0.03 & 0.19 & -0.36 & 0.99 & 37.50 & -3.17 \\
\hline
\end{tabular}

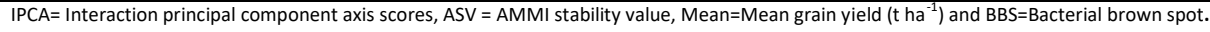

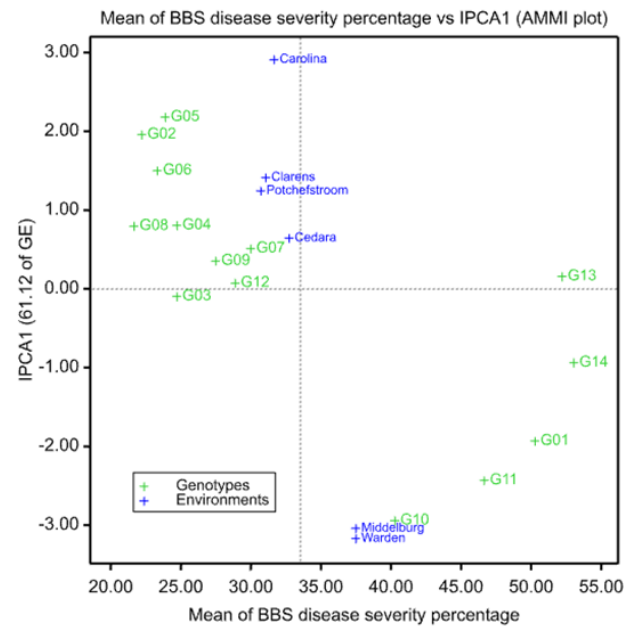

Fig 3. AMMI biplot showing the genotype adaptation based on BBS severity across six environments.

Table 4. Ranking of the best four dark red kidney (DRK) dry bean lines for grain yield and BBS disease severity over six environments.

\begin{tabular}{|c|c|c|c|c|c|c|c|c|c|c|c|c|}
\hline \multirow[b]{2}{*}{ Env } & \multicolumn{6}{|c|}{ Ranking based on grain yield } & \multicolumn{6}{|c|}{ Ranking based on BBS severity } \\
\hline & $\begin{array}{l}\text { Mean } \\
\text { grain } \\
\text { yield }\end{array}$ & $\begin{array}{l}\text { IPCA } \\
\text { score }\end{array}$ & $1^{\text {st }}$ & $2^{\text {nd }}$ & $3^{\text {rd }}$ & $4^{\text {th }}$ & $\begin{array}{l}\text { Mean } \\
\text { BBS } \\
\text { severity }\end{array}$ & $\begin{array}{l}\text { IPCA } \\
\text { score }\end{array}$ & $1^{\text {st }}$ & $2^{\text {nd }}$ & $3^{\text {rd }}$ & $4^{\text {th }}$ \\
\hline Carolina & 1.04 & -0.63 & G08 & G06 & G02 & G03 & 22.99 & 2.91 & G08 & G02 & G03 & G05 \\
\hline Cedara & 1.10 & 0.04 & G13 & G02 & G11 & G06 & 22.58 & 0.64 & G05 & G04 & G03 & G06 \\
\hline Clarens & 1.22 & 0.41 & G04 & G04 & G01 & G08 & 19.58 & 1.41 & G08 & G06 & G12 & $\mathrm{G} 02$ \\
\hline Middel & 1.10 & -0.89 & G06 & G03 & G02 & G05 & 21.67 & -3.04 & $\mathrm{G} 02$ & G06 & G05 & G03 \\
\hline Potch & 2.84 & 0.53 & G07 & G10 & G13 & G08 & 20.84 & 1.24 & G03 & G08 & $\mathrm{G} 02$ & G06 \\
\hline Warden & 1.30 & 0.53 & G14 & G07 & G08 & G01 & 21.25 & -3.17 & G08 & G02 & G05 & G06 \\
\hline
\end{tabular}

Env=Environment, Potch=Potchefstroom, Middel=Middelburg, Mean =Mean grain yield $\left(\mathrm{t} \mathrm{ha}^{-1}\right)$ and $\mathrm{BBS}=$ Bacterial brown spot. 


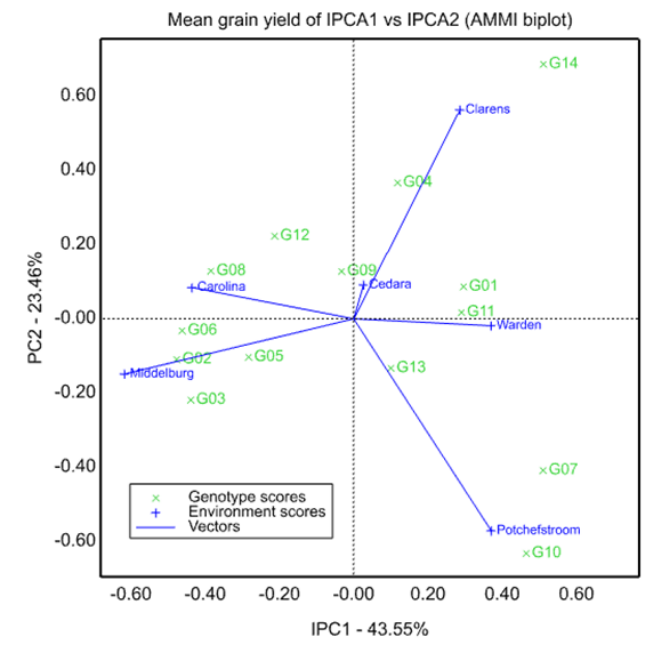

Fig 4. IPCA1 vs IPCA2 plot for grain yield of 14 DRK dry bean across six environments in South Africa.

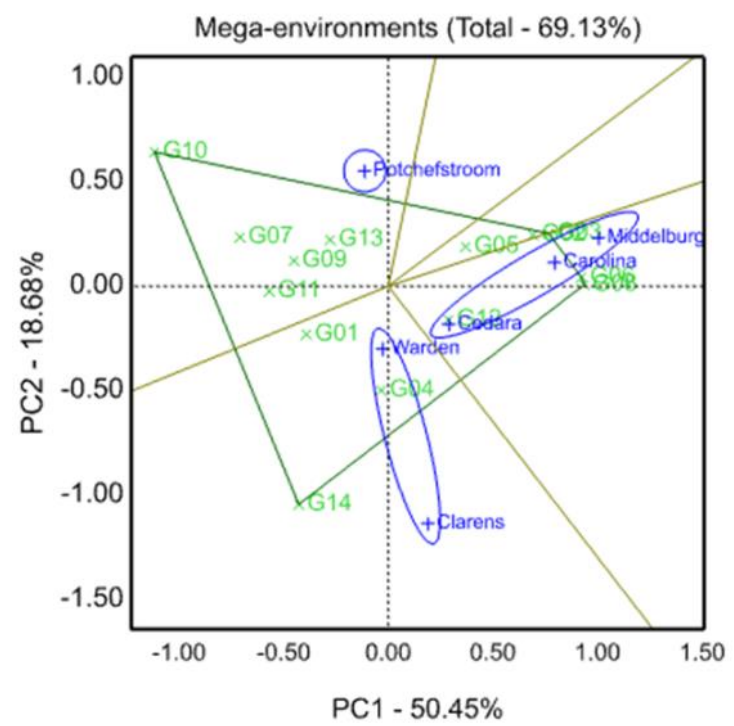

Fig 5. Mega-environment analysis for grain yield of 14 genotypes across six environments in South Africa.

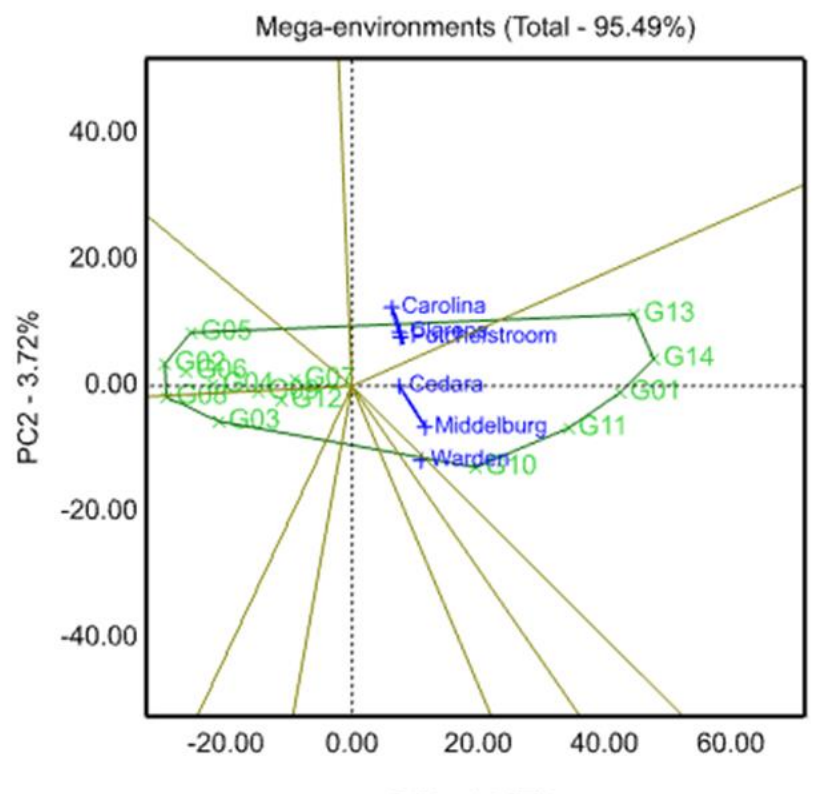

PC1 - 91.77\%

Fig 6. Mega-environment analysis for bacterial brown spot severity of 14 DRK dry bean genotypes across six environments in South Africa. 


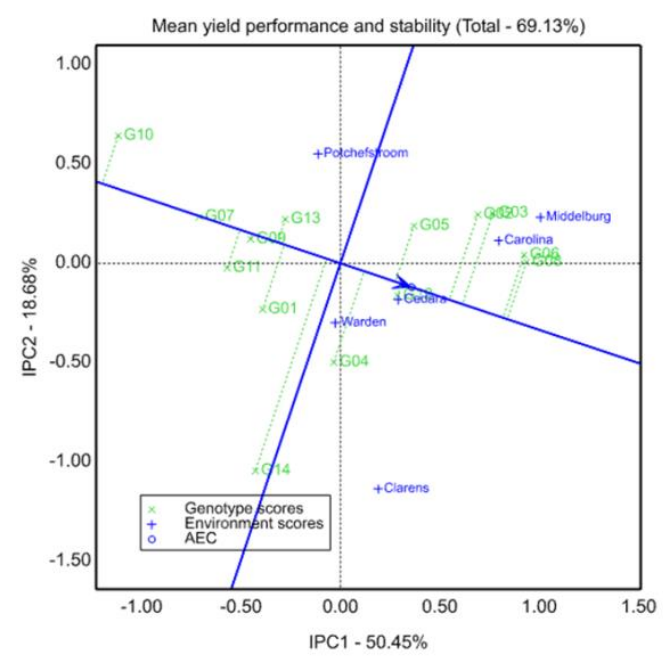

Fig 7. Mean grain yield performance and stability of 14 DRK dry bean genotypes across six tested environments.

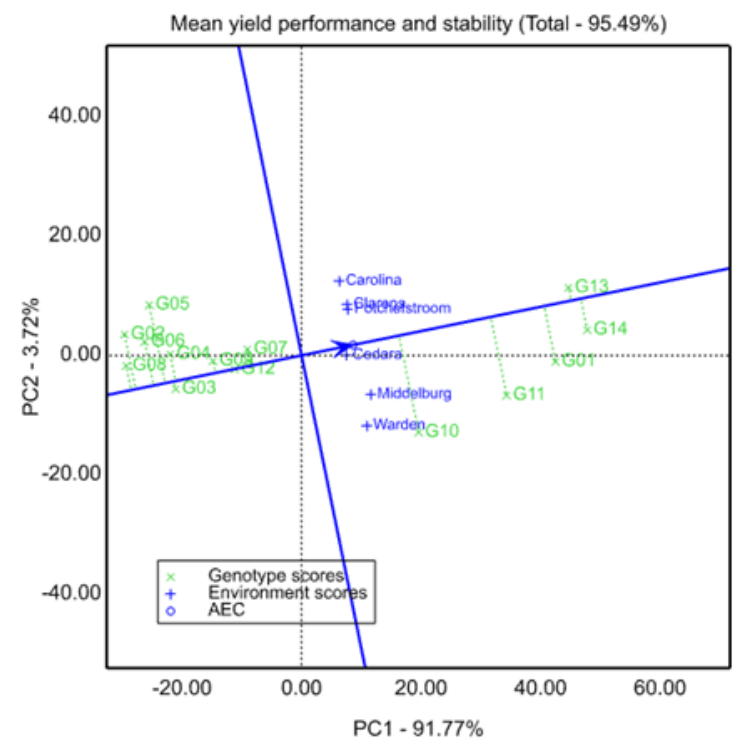

Fig 8. Mean bacterial brown spot disease severity and stability of 14 DRK dry bean genotypes over six environments.

Genotype, G12, had the lowest static stability (0.26) and Wricke's ecovalence stability coefficient $(0.20)$ of grain yield ( $\mathrm{t} \mathrm{ha}{ }^{-1}$ ), while genotype G08 had the lowest cultivar superiority, difference of pair of ranks and variances of ranks stability coefficient of grain yield of $0.12,2.43$ and 4.38 , respectively (Table S5). Genotype G06 had the lowest mean ranks stability coefficient of grain yield of 4.17 (Table S5).

\section{Discussion}

This study evaluated fourteen dark red kidney dry bean genotypes for grain yield, BBS disease resistance, and stability across six environments. The significance of main effects of genotypes and environments indicated broad adaptation of some genotypes across tested sites, while GEI significance indicated that some genotypes were specifically adapted to certain environments.

The two DRK cultivars used as checks viz. G13 and G14, both had relatively low grain yield of $1.35 \mathrm{t} \mathrm{ha}^{-1}$ and $1.43 \mathrm{t} \mathrm{ha}^{-1}$, respectively, and high BBS severity of $48.89 \%$ and $49.44 \%$, respectively, indicating poor adaptability under local conditions. Genotype G12 (1.46 t ha ${ }^{-1}$ ) had a high yield, low BBS severity and was stable, and revealed broad adaptation across six environments, while G08 $\left(1.77 \mathrm{t} \mathrm{ha}^{-1}\right), \mathrm{G} 06(1.70 \mathrm{t}$ ha $\left.{ }^{-1}\right)$, G03 (1.63 t ha $\left.{ }^{-1}\right)$, G02 (1.56 t ha $\left.{ }^{-1}\right)$, G05 (1.48 $\left.\mathrm{t} \mathrm{ha}^{-1}\right)$ and $\mathrm{GO} 4$ (1.45 $\left.\mathrm{t} \mathrm{ha}^{-1}\right)$ had high grain yield, low BBS severity and were unstable, and therefore revealed specific adaptation. These genotypes had grain yields above the grand mean and the best check (AC Calmont) both with 1.43 $\mathrm{t} \mathrm{ha}^{-1}$ and with BBS severity below the grand mean (31.90\%) and the best performing cultivar (48.89\%). These genotypes selected for broad and specific adaptation had both higher grain yield and lower BBS severity than the grand mean and the best local check. Mortazavian et al. (2014) indicated that the genotypes with a high mean performance and low ASV revealed broad adaptation and those that had both high mean performance and high stability, revealed specific adaptation. However, in respect of BBS severity (\%), a genotype with a low percentage value is desirable especially if its ASV for the same is low.

The AMMI analysis of variance revealed that the IPCA 1- 4 axes were greatly significant $(P<0.001, P<0.01)$. Four IPCAs 
explained $43.56 \%, 23.47 \%, 21.72 \%$ and $8.19 \%$ of the total sum square GEI of DRK dry bean genotypes, respectively. Four IPCAs accounted for $96.94 \%$ of GEI and $3.06 \%$ of the remaining pooled GEI. Mortazavian et al. (2014) found that IPCA1 (28.62\%), IPCA2 (24.79\%), IPCA3 (13.85\%) and IPCA4 (10.17\%) accounted $77.43 \%$ of the variation of GEI in their analysis of grain and stability in barley tested within sites in Iran. Furthermore, Mohammadi et al. (2015) in study of yield stability of durum wheat genotypes, found that IPCA1 (33.74\%), IPCA2 (19.00\%), IPCA3 (15.48\%) and IPCA4 (10.10\%) account for $78.32 \%$ of the variation of GEI for grain yield in wheat.

The genotype G07 had a positive signal IPCA1 score of 0.52 , and had specific adaptation to Potchefstroom with a positive signal IPCA1 score of 0.53 and Warden with a positive signal IPCA1 score of 0.53 . Similarly, G02, with a negative signal IPCA1 score of -0.49 , had adaptation to Carolina with a negative signal IPCA1 score of -0.63 . However, many genotypes showed this relationship between the signal of IPCA1 of genotype and IPCA1 of environment. Karimizadeh et al. (2016) reported that genotypes with high IPCA1 scores were adapted to specific sites with IPCA1 scores of the similar or identical sign.

This study grouped the six environments in three megaenvironments. The first mega-environment for grain yield was Potchefstroom with genotypes G07, G10, G13, G11 and G09. The second included Cedara, Carolina and Middelburg with genotypes such as G06, G08, G12, G02, G03 and G05, while genotypes $\mathrm{G} 14, \mathrm{G} 04$ and $\mathrm{G} 01$ were adapted to the third mega-environment, which included Clarens and Warden. However, for BBS severity Warden formed its own mega-environment, while Carolina, Clarens and Potchefstroom formed another one, and the last megaenvironment included Cedara and Middelburg. Kendal (2016) indicated that sites with identical reactions to genotype performance were assembled together (megaenvironments) and substituted the representative environment of the region, in which the genotype was grown.

\section{Materials and Methods}

\section{Plant material}

Fourteen advanced DRK) breeding lines, coded G01-G14 from the Agricultural Research Council-Grain Crops Institute Breeding Program (ARC-GCl-BP) were included (Table S1). All genetic materials were red seeded and were of Type II growth habit as described in the field book evaluation (Muedi et al., 2015a). The Type II is indeterminate and has an erect growth habit with an erect stem and more nodes and internodes than Type I, and continues to grow during flowering (Muedi et al., 2015a). The main selection criteria were the yield, resistance to shattering, lodging, disease resistance and seed quality. Genotypes G13 and G14, are well known dark red kidney beans in the USA known as Montcalm and AC Calmont, respectively, and were included as checks (Table S1).

\section{Experimental sites and the weather data}

Fig 1. indicates the locations of the study was done. Furthermore, the geographic location and weather data for experimental sites are presented in Table 2. The localities were Warden and Clarens (Free State), Middelburg, and Carolina (Mpumalanga), Cedara (KwaZulu-Natal) and Potchefstroom (North-West). The mean temperature was lowest at Carolina $\left(24.4^{\circ} \mathrm{C}\right)$ and highest at Middelburg $\left(28.2^{\circ} \mathrm{C}\right.$ ), whereas Middelburg had the lowest rainfall (349 $\mathrm{mm})$, and Cedara had the highest rainfall $(931 \mathrm{~mm})$. Clarens, Warden, Middelburg, and Carolina were planted on-farm, whereas Potchefstroom and Cedara trials were on-station.

\section{Design and management of trials}

The fourteen DRK dry bean genotypes were laid out in a $2 \mathrm{x}$ 7 alpha lattice design with three replicates at each site. Each incomplete block had seven $5 \mathrm{~m}$ four-row plots of DRK dry bean lines. Inter-row distance was $76 \mathrm{~cm}$, whereas plant-to-plant spacing within the row was $7.5 \mathrm{~cm}$ resulting in 75 plants in each row. Two border rows were planted around the four sides of the experiment and the weeds were controlled manually. Potchefstroom was the only site with irrigation and the others are all dry land. Inorganic fertilizers were applied at a rate of $42.3 \mathrm{~kg} \mathrm{ha}^{-1} \mathrm{~N}, 22.3 \mathrm{~kg}$ $\mathrm{ha}^{-1} \mathrm{P}$, and $18.4 \mathrm{~kg} \mathrm{ha}^{-1} \mathrm{~K}$.

\section{Data collection and analysis}

Data were collected per plot basis on two middle rows in each plot. The grain yield per plot was weighed and converted to tons per hectare $\left(\mathrm{t} \mathrm{ha}^{-1}\right)$. BBS severity was rated using a standardised CIAT scale of 1 (resistant or immune) to 9 (susceptible or disease) (Pastor-Corrales and Schoonhoven, 1987) and converted to the percentage of leaf area diseased for the total plot. The scores were transformed into percentages $1=5 \%, 2=15 \%, 3=25 \%, 4=35 \%, 5=45 \%, 6=$ $55 \%, 7=65 \%, 8=75 \%$ and $9=85 \%$. Data were analysed using the unbalanced analysis of variance in Genstat ${ }^{\circledR}$ 18th edition (Payne, 2011), and the means were separated by the least significant difference (LSD) at $P=0.05$. Grain yield, BBS severity, and stability of performance were analysed using univariate and multivariate stability parameters.

\section{Analysis of variance}

Data analysis was performed using ANOVA across locations and at each location.

The ANOVA model (Equation 1) for combined analysis was:

$\mathrm{Y}_{i j k l}=\mu+\mathrm{G}_{i}+\mathrm{E}_{\mathrm{j}}+\mathrm{R}_{\mathrm{k}(\mathrm{j})}+\mathrm{B}_{\mathrm{l}(\mathrm{jk})}+\mathrm{GE}_{\mathrm{ij}}+\varepsilon_{\mathrm{ijkl}}$

Equation 1

where Yijkl is the response corresponding to the $i^{\text {th }}$ genotype in $j^{\text {th }}$ environment, $k^{\text {th }}$ replication within environment and $l^{\text {th }}$ incomplete block within replication; $\mu$ is the grand mean; $G_{i}$ is the genotype effect $i=1,2 \ldots, 14 ; \mathrm{E}_{j}$ is the environment effect $j=1,2 \ldots, 6 ; \mathrm{R}_{k(j)}$ is the replication effect $k=1,2,3 ; \mathrm{B}_{l(j k)}$ is the block effect $I=1,2 ; \mathrm{GE}_{i j}$ is the genotype $\times$ environment interaction effect; and $\varepsilon_{i j k l}$ is the random error.

\section{Additive main effect and multiplicative interactions}

The additive main effect and multiplicative interaction (AMMI) analysis partitioned the covariance components into additive (ANOVA) and multiplicative (biplot) effects (Gauch $J r$, 1988). The biplot allows the visualized relationship between IPCA and the means of genotypes and environment 
(Gauch and Zobel, 1996). The large IPCA scores, regardless of the signal, revealed the specific adapted genotype and the low IPCA scores (positive/negative) revealed a broad adapted genotype (Gauch, 2006). The AMMI model (Equation 2) contains additive terms for main effects of genotype and environment together, as well as multiplicative terms that accounts for interaction (Payne, 2011).

$\mathrm{Y}_{\mathrm{ij} j} \mu+g_{i}+e_{j}+\sum_{n=1}^{N} \alpha_{n} \gamma \quad \delta_{j n}+\epsilon_{i j k}$

Equation 2

Where $Y_{i j}$ is the performance of the genotype $(i=1,2, . ., 14)$ in the $j$ environment $(j=1,2, . ., 6) ; \mu$ is the grand mean; $g_{i}$ and ej are the genotype and environment deviations from the grand mean, respectively; $\boldsymbol{\alpha}_{\mathrm{n}}$ is the eigenvalue of the IPCA analysis axis $\mathrm{n} ; \boldsymbol{\gamma}_{\text {in }}$ and $\delta_{\text {jn }}$ are the genotype and environment principal components scores for axis $\mathrm{n}$; $\mathrm{N}$ is the number of principal components retained in the model and $\epsilon_{i \mathrm{ik}}$ is the error term.

\section{AMMI stability value}

AMMI stability values (ASV) (Equation 3) were used to identify cultivars that showed specific or general adaptation across environments (Purchase, 1997).

$\mathrm{ASV}=\sqrt{\left[\left(\frac{\text { SSIPCA1 }}{\text { SSIPCA2 }}\right)(\text { IPCA1score })\right]^{2}+(\text { IPCA2score })^{2}}$

Equation 3

Where: SS = sum of squares, IPCA1 = the first interaction principal component axis and IPCA2 = the second interaction principal component axis.

\section{Genotype main effect plus genotype by environment interaction}

The GGE biplot identifies mega environment (which-wonwhere), mean performance, and stability (Yan et al., 2000). The GGE biplot was constructed using Equation 4 (Yan et al., 2000).

$\mathrm{Y}_{\mathrm{ij}} \mu+e_{j}+\sum_{n=1}^{N} \alpha_{n} \gamma \quad \delta_{j n}+\epsilon_{i j k} \quad$ Equation 4

Where $Y_{i j}$ is the yield of the $i$ genotype $(i=1,2 . ., 14)$ in the $j$ environment $(j=1,2 . ., 6) ; \mu$ is then grand mean; ej are the environment deviations from the grand mean; $\boldsymbol{\alpha}_{\mathrm{n}}$ is the eigenvalue of the principal component (PC) axis n; $\boldsymbol{\gamma}_{\text {in }}$ and $\delta_{\text {jn }}$ are the genotype and environment principal components scores for axis $n$, respectively; $N$ is the number of principal components retained in the model and $\epsilon_{\mathrm{ijk}}$ is the error term.

\section{Univariate stability parameters}

The stability parameters are useful in characterizing genotypes by showing their relative performance in various environments (Oladosu et al., 2017). Univariate models such as cultivar superiority, static stability, mean ranks, Wricke's ecovalence, difference of pairs ranks and variances of ranks were used for stability evaluation (Oladosu et al., 2017). A genotype was regarded stable when the univariate stability coefficient of grain yield did not differ significantly from zero (Chipeta et al., 2017). The large stability coefficients revealed genotypes with specific adaptation to high yielding environments, while low stability coefficient showed genotypes with broad adaptation over environments (Chipeta et al., 2017).

\section{Conclusion}

Genotype G12 (1.46 $\mathrm{t} \mathrm{ha}^{-1}$ ) had high yield, low BBS severity, and broad adaptation across six environments. Genotypes G08 (1.77 t ha $\left.{ }^{-1}\right)$, G06 (1.70 t ha $\left.{ }^{-1}\right)$, G03 (1.63 t ha $\left.{ }^{-1}\right), \mathrm{G} 02$ $\left(1.56 \mathrm{t} \mathrm{ha}^{-1}\right), \mathrm{G} 05\left(1.48 \mathrm{t} \mathrm{ha}^{-1}\right)$, and G04 (1.45 $\left.\mathrm{t} \mathrm{ha}^{-1}\right)$ had high grain yield, low BBS severity and were unstable, revealing specific adaptation. These genotypes had grain yield above the grand mean and the best performing cultivar, namely $1.43 \mathrm{t} \mathrm{ha}^{-1}$ and with BBS severity below the grand mean (31.90\%) and the best performing cultivar (48.89\%), namely AC Calmont. These genotypes can be recommended as cultivars for release or used as parents in a breeding programme to improve the grain yield and BBS resistance of the dark red kidney beans.

\section{Acknowledgements}

The authors are grateful to the Alliance for Green Revolution in Africa (AGRA) for funding support. The Agricultural Research Council-Grain Crop Improvement Breeding program ARC-GCl-BP) is acknowledged for providing planting material and expertise, and managing field trials.

\section{References}

Abuali Al, Abdelmula AA, Khalafalla MM, Hamza NB, Abdalla $A H$, Idris AE (2014) Assessment of yield stability and adaptability of parental inbred lines and f1-hybrids of grain maize (Zea mays L.) using AMMI analysis. British Biotechnology Journal. 4: 339-349.

Agyeman A, Parkes E, Peprah B (2015) AMMI and GGE biplot analyses of root yield performance of cassava genotypes in forest and coastal ecologies. International Journal of Agricultural Policy and Research. 3: 122-132.

Chipeta MM, Melis R, Shanahan P, Sibiya J, Benesi IR (2017) Genotype $X$ environment interaction and stability analysis of cassava genotypes at different harvest times. Journal of Animal and Plant Sciences. 27: 901-919.

Dia M, Wehner TC, Hassell R, Price DS, Boyhan GE, Olson S (2016) Genotypex environment interaction and stability analysis for watermelon fruit yield in the United States. Crop Science. 56: 1645-1661.

Dlamini T, Nalley L, Tsiboe F, Barkley A, Shew A (2017) The economic impact of the South African Agricultural Research Council's dry beans breeding program. Journal of Agricultural and Applied Economics. 49: 232-250.

FAO (2014) WFP-The State of Food Insecurity in the World 2014 strengthening the enabling environment for food security and nutrition, 3rd. Rome. Italy.

Gauch HG (2006) Statistical analysis of yield trials by AMMI and GGE. Crop Science. 46: 1488-1500.

Gauch JHG (1988) Model selection and validation for yield trials with interaction. Biometrics. 44: 705-715.

González A, Monteagudo A, Casquero P, Deron A, Santalla M (2006) Genetic variation and environmental effects on agronomical and commercial quality traits in the main European market classes of dry bean. Field Crops Research. 95: 336-347.

Karimizadeh R, Asghari A, Chinipardaz R, Sofalian O, Ghaffari A (2016) Determining yield stability and model selection by AMMI method in rain-fed durum wheat genotypes. Turkish Journal of Field Crops. 21: 174-183. 
Kendal E (2016) GGE biplot analysis of multienvironment yield trials in barley (Hordeum vulgare L.) cultivars. Ekin Journal of Crop Breeding and Genetics. 2: 90-99.

Kimani P, Buruchara R, Ampofo K, Pyndji M, Chirwa R, Kirkby $R$ (2005) Breeding beans for smallholder farmers in Eastern, Central, and Southern Africa: Constraints, achievements, and potential. PABRA Millennium Workshop. 4: 11-12.

Mohammadi M, Sharifi P, Karimizadeh R, ALT JJ, Khanzadeh $\mathrm{H}$, Hosseinpour T (2015) Stability of grain yield of durum wheat genotypes by AMMI model. Agriculture and Forestry Sumarstvo. 61: 181-182.

Mortazavian S, Nikkhah H, Hassani F, Sharif H M, Taheri M, Mahlooji M (2014) GGE biplot and AMMI analysis of yield performance of barley genotypes across different environments in Iran. Journal of Agricultural Science and Technology. 16: 609-622.

Muedi HT, Fourie D, McLaren NW (2015) Distribution and severity of bacterial brown spot on dry beans in South Africa: an update. South African Journal of Science. 111: 16.

Muedi HTH (2015) Reaction of selected common bean germplasm accessions to bacterial brown spot in South Africa. Crop Protection. 77: 87-93.
Oladosu Y, Rafii MY, Abdullah N, Magaji U, Miah G, Hussin G (2017) Genotypex Environment interaction and stability analyses of yield and yield components of established and mutant rice genotypes tested in multiple locations in Malaysia. Acta Agriculturae Scandinavica, Section B. Soil and Plant Science. 7: 1-17.

Payne RW (2011) GenStat released 14 reference manual, part 2 directives, 3 rd edition. VSN International, Hemek Hempstead, UK.

Pastor-Corrales, M. and A. Schoonhoven (1987) Standard system for the evaluation of bean germplasm, 3rd edition. Ciat-Cáli, Colômbia.

Purchase J, Hatting H, Van DC (2000) Genotypex environment interaction of winter wheat (Triticum aestivum L.) in South Africa: II. Stability analysis of yield performance. South African Journal of Plant and Soil. 17: 101-107.

Purchase JL (1997) Parametric analysis to describe genotype $x$ environment interaction and yield stability in winter wheat. 1th ed. University of the Free State. South Africa.

Serfontein J (1994) Occurrence of bacterial brown spot of dry beans in the Transvaal province of South Africa. Plant Pathology. 43: 597-599.

Yan W, Hunt L, Sheng Q, Szlavnics Z (2000) Cultivar evaluation and mega-environment investigation based on the GGE biplot. Crop Science. 40: 597-605. 